\title{
KOMUNIKASI, PARTISIPASI, DAN KONFLIK DALAM PEMBERDAYAAN MASYARAKAT
}

\author{
Shinta Prastyanti \\ Universitas Jenderal Soedirman, Purwokerto \\ shinta_prastyanti@yahoo.com
}

\begin{abstract}
This research aims to analysis the connections among communication, participation, and conflict within community empowerment. As we know that community empowerment is not a single activity, but is an ongoing process which is cannot be separated to other variables. Without participation from all of the stakeholders involved, the community empowerment cannot reach its goal. This participation gives an open and greater opportunity for all stakeholders to get involved in the process, even to control it. Unfortunately, a greater power for the stakeholder precisely will give an unproductive impact when it correlated to a hidden interest which often tends to give an advantage to their own group. Furthermore, it cannot be denied if the emerging of conflict which is difficult to be solved. In this part, communication plays an important role to prevent it from that conflict when there is a mutual understanding among all of the stakeholders. This effective communication will also contribute to conflict resolution.
\end{abstract}

Key words: communication, participation, conflict, community empowerment, mutual understanding

\section{PENDAHULUAN}

Komunikasi adalah suatu aktifitas sehari-hari yang tidak bisa dihindari. Komunikasi terjadi tidak hanya dengan diri sendiri, dengan orang lain, maupun dalam skala yang lebih luas yakni dalam pemberdayaan masyarakat. Ketika berbicara mengenai pemberdayaan masyarakat maka istilah partisipasi melekat di dalamnya. Hal tersebut adalah wajar mengingat partisipasi dari para pemangku kepentingan ditengarai turut berkontribusi atas keberhasilan program pemberdayaan masyarakat.

Proses partisipasi juga tidak bisa lepas dari unsur komunikasi. Sejauh ini komunikasi diposisikan hanya sebagai alat untuk mensukseskan program-program pembangunan, termasuk pemberdayaan masyarakat. Melalui komunikasi, komunikator pemberdayaan masyarakat menyampaikan pesan kepada seluruh stakeholder agar bersedia berpartisipasi dalam program pemberdayaan masyarakat tersebut. Di sisi lain, besarnya partisipasi dari para stakeholder dalam proses pemberdayaan masyarakat acapkali sulit dihindari terjadinya konflik baik yang bersifat horisontal maupun vertikal. Jika terjadi konflik lantas di mana posisi komunikasi dalam hal ini? Apakah komunikasi dapat menjadi sebuah solusi atau justru dapat memperkeruh konflik yang terjadi?

Pertanyaan-pertanyaan tersebut di atas menjadi dasar bagi peneliti untuk menganalisis le bih ja $\mathrm{ah} \quad \mathrm{men}$ e $\mathrm{n} \mathrm{a} \mathrm{i}$ 
komunikasi, partisipasi dan konflik dalam pemberdayaan masyarakat. Agar dapat dilakukan pembahasan yang mendalam dan menghasilkan simpulan yang akurat maka peneliti melakukan kajian terhadap berbagai literatur terkait.

Menurut Littejohn \& K.A. Foss (2011) komunikasi adalah pentransmisian informasi. Dari definisi tersebut dapat diketahui bahwa dalam proses transmisi informasi berarti terdapat 2 (dua) pihak, yakni yang mentransmisikan informasi serta pihak yang menerima informasi. Dalam proses transmisi informasi pasti juga mengandung pesan yang disalurkan melalui saluran atau media tertentu, dan diharapkan akan menimbulkan efek seperti yang diharapkan oleh pengirim informasi. Namun sayangnya mendefinisikan komunikasi sebagai pentrasnmisian informasi semata tidak memberikan jaminan bahwa informasi tersebut akan diterima bahkan difahami oleh komunikan. Kondisi tersebut menjadikan informasi yang disampaikan "sulit untuk dikontrol", dan bukan tidak mungkin tanpa pemahaman yang utuh atas informasi maka dapat berpotensi menimbulkan benih-benih konflik. Namun demikian, tanpa proses transmisi informasi niscaya setiap stakeholder tidak akan dapat berbagi dan memperoleh informasi yang memadai mengenai program pemberdayaan masyarakat yang akan maupun sedang dilakukan.

Selain kurang mencakup aspek penerimaan ataupun pemahaman bagi penerima informasi, definisi tersebut tampaknya menempatkan pengirim informasi pada posisi "yang lebih dominan" dibanding penerima informasi. Ketidaksetaraan posisi dalam proses transmisi informasi akan melahirkan komunikasi yang tidak efektif dan cenderung bersifat linier, mengingat komunikasi efektif akan terjadi apabila ada equality atau kesamaan dalam memberi dan menerima informasi. Untuk memperbaiki kelemahan tersebut muncullah model komunikasi yang konvergen (Rogers \& Kincaid, 1986). Dalam model ini memungkinkan penerima mengontrol makna yang dihasilkan dari interaksi yang bersifat dialogis di antara 2 (dua) komunikator (Bakti, 2004). Berkaiatan dengan kelebihan yang ditawarkan oleh model yang bersifat konvergen tersebut, maka model ini dapat menjadi satu pilihan yang lebih tepat dalam memotret sebuah proses pemberdayaan masyarakat. Apalagi jika mengingat proses pemberdayaan masyarakat yang nota bene menganut model bottom up sehingga informasi tidak hanya berasal dari komunikator kepada masyarakat, akan tetapi juga sebaliknya yakni masyarakat dapat menyampaikan informasi kepada pihak lain sehingga terjadi pertukaran posisi.

Definisi yang lebih lengkap disampaikan oleh Mardikanto (2010) yang melihat komunikasi sebagai upaya menyampaikan sesuatu (informasi) kepada masyarakat luas agar informasi tersebut diketahui dan menjadi "milik bersama". Definisi kedua ini tidak hanya menekankan pada proses pentransisian informasi, namun lebih jauh hingga tahap informasi tersebut diketahui, 
bahkan menjadi "milik bersama". Artinya adalah, ketika informasi sudah menjadi milik bersama maka diharapkan akan berkorelasi pada tingkat partisipasi yang pada akhirnya berujung pada keberhasilan dan keberlanjutan program pemberdayaan masyarakat itu sendiri.

Definisi partisipasi hingga saat ini masih menuai perdebatan dari berbagai ilmuwan. Menurut Jacobson \& Store (2004) partisipasi terkadang didefinisikan sebagai keterlibatan dalam pelaksanaan, dalam mendesign program, ataupun keduanya, sehingga pada berbagai literatur partisipasi cenderung berfokus pada proses di tingkat desa. Jacobson \& Store juga menyampaikan bahwa idealnya partisipasi dimulai dengan 'ideal speech" dan "public sphere,", yang tidak hanya melihat partisipasi pada perspektif proses di level tertentu saja. Kenyataan di lapangan memang menunjukkan bahwa partisipasi tidak hanya dimulai pada tingkat desa serta tidak hanya terbatas pada bahasan mengenai pada tingkat mana partisipasi tersebut dimulai. Gagasan Jacobson \& Store di atas memberikan definisi yang lebih bermanfaat untuk menganalisasi komunikasi partisipasi secara teoritis dan juga dalam tataran pelaksanaan.

Pendapat yang agak berbeda dengan tidak membatasi partisipasi pada level desa disampaikan oleh Rahman (1993) yang menyatakan bahwa partisipasi sudah dikonseptiualisasikan sebagai proses yang aktif dari partisipan dalam mengambil inisiatif dan tindakan yang distimulasi oleh pemikiran mereka sendiri sehingga dapat melakukan kontrol yang efektif. Pendapat Rahman (1993) memberikan ruang pembahasan yang lebih luas pada aspek individu dan menempatkan individu sebagai pihak yang aktif. Keaktifan individu tidak hanya terbatas pada tataran perencanaan dan pelaksanaan saja, namun juga berlanjut pada proses kontrol. Pendapat Rahman tersebut sangat bermanfaat dalam menganalisis proses pemberdayaan masyarakat, khususnya pada as pek partisipasi, mengingat individu/stakeholder merupakan salah satu komponen kunci dalam upaya mewujudkan tujuan utama pemberdayaan masyarakat.

Meskipun para stakeholder termasuk masyarakat telah diberikan kewenangan untuk terlibat secara langsung maupun tidak langsung dalam pemberdayaan masyarakat, sayangnya hal tersebut justru "memisahkan" antara masyarakat yang berpartisipasi dengan yang tidak. Berkaitan dengan hal tersebut, Shortall (2008) berpendapat bahwa program-program pembangunan pedesaan seringkali memberikan interpretasi yang salah mengenai proses sosial dari partisipasi sehingga berdampak pada pemberian label pada kelompok-kelompok yang secara sosial tidak ikut terlibat. Pemberian label justru akan lebih "mengasingkan" kelompok-kelompok yang tidak turut berpartisipasi dan juga kontraproduktif terhadap semangat pemberdayaan masyarakat itu sendiri. Dampak lain yang bisa timbul adalah terciptanya gap di antara anggota masyarakat apalagi ketika pemberdayaan masyarakat tersebut berhasil meningkatkan kondisi sosial, ekonomi, politik masyarakat, khususnya bagi masyarakat yang ikut berpartisipasi. 
Kesenjangan yang terjadi di dalam masyarakat dapat berpotensi untuk memunculkan konflik. Konflik tersebut dapat terjadi pada skala yang lebih luas yakni pada masyarakat secara keseluruhan, maupun terbatas dalam proses pemberdayaan masyarakat itu sendiri. Hal tersebut menjadi mungkin terjadi mengingat masing-masing stakehoder mempunyai kewenangan untuk mengambil inisiatif dan tindakan, bahkan melakukan kontrol terhadap jalannya pemberdayaan masyarakat. Pada kondisi tersebut kesalahan dalam mempersepsi sebuah informasi ataupun penerimaan informasi yang tidak lengkap dapat memicu munculnya kesalahpahaman yang kemudian sangat mungkin berlanjut pada konflik. Bahkan konflikpun dapat disebabkan oleh alasan-alasan yang tidak rasional. Mengenai hal ini, Garfinkel, et.al. (2000) menyampaikan bahwa konflik juga dilihat sebagai hasil dari salah persepsi, informasi yang tidak lengkap, ataupun sesuatu yang tidak rasional. Berbeda dengan Garfinkel, et.al.,, Tjosvold (1998) lebih melihat konflik sebagai tindakan yang bertentangan daripada pendapat yang berseberangan. Pendapat Tjosvold tersebut menegaskan bahwa konflik tidak hanya sekedar terjadinya perbedaan pendapat namun sudah lebih jauh lagi, yakni pada tataran pertentangan tindakan.

Meskipun demikian, konflik bukannya tidak dapat diselesaikan. Rahim (2000) menegaskan bahwa konflik dapat diatasi dengan jalan integrasi, kesediaan untuk membantu, dominasi, menghindar, juga berkompromi. Sejalan dengan Rahim, Tjosvold (1998) menambahkan bahwa komunikasi yang hangat, membangun kerjasama, hubungan yang saling menguntungkan, mengekplorasi pendapat yang berbeda, dan lain-lain juga dapat menjadi solusi dalam mengatasi konflik.

Dari beberapa pendapat di atas peneliti berpendapat bahwa komunikasi efektif yang menitikberatkan pada kesamaan pengertian dapat menjadi salah satu solusi yang tepat untuk menyelesaikan konflik yang muncul, termasuk di antaranya yang terjadi dalam proses partisipasi para stakeholder dalam pemberdayaan masyarakat.

Banyak pendapat yang disampaikan oleh berbagai ilmuwan mengenai pemberdayaan masyarakat. Salah satu di antaranya dikemukakan oleh Page \& Czuba (1999) yang melihat pemberdayaan masyarakat sebagai sebuah proses memperkuat daya mas yarakat (kapasitas untuk m e n g i m p le m e n t a s i k a n ) d a n mempergunakannya dalam kehidupan serta lingkungannya dengan melaksanakan isu-isu yang menurut mereka penting. Pendapat tersebut menyiratkan bahwa pemberdayaan masyarakat seyogyanya disesuaikan dengan kebutuhan dan kondisi riil masyarakat sehingga dapat memberikan dampak positif secara maksimal bagi masyarakat.

Tidak berbeda jauh dari pendapat sebelumnya, Schuftan (1996); Noya \& Clarence (2009) menyatakan bahwa pemberdayaan masyarakat bukanlah sebuah hasil dari aktifitas tunggal tetapi proses yang terus berjalan. Proses 
tersebut membuat masyarakat memahami, meningkatkan dan mempergunakan kapasitas yang dimilikinya untuk melakukan kontrol yang lebih baik dan memperoleh daya bagi kehidupannya. Senada dengan Schuftan serta Page \& Czuba, Pigg (2002) mendefinisikan pemberdayaan sebagai upaya memberikan atau menyediakan kekuasaan buat orang lain. Transfer kekuasaan/daya tersebut memberikan kesempatan yang lebih besar kepada masyarakat untuk ikut berpartisipasi sejak identifikasi permasalahan hingga mengontrol dan mengevaluasi pelaksanaan program pemberdayaan masyarakat. Idealnya transfer kekuasaan tersebut tidak berdasarkan atas paksaan atau tekanan yang dapat berakibat kontraproduktif, karena tekanan dapat secara signifikan mempengaruhi kemampuan masyarakat dalam mengontrol dan menerima tanggungjawab (Sympson, et. al. , 2003). Selain meningkatkan daya masyarakat agar lebih memiliki kesempatan untuk memperbaiki kehidupannya, lebih lanjut Bhattacharyya (2004) juga menyatakan bahwa tujuan dari pemberdayaan masyarakat adalah mewujudkan solidaritas dengan menerapkan prinsip-prinsip self help, merasa membutuhkan, serta partisipasi. Berkaitan dengan solidaridas, Amsperger \& Varoufakis (2003) menambahkan bahwa masyarakat dapat memberikan pendapat/pandangan yang simpatik atas kondisi yang dialami orang lain. Kesadaran pada tataran masyarakat ini didefinisikan sebagai sebuah kekuatan dan kepercayaan diri masyarakat dalam kaitannya dengan keberlanjutan pertisipasi mereka (Kwiatkowski, 2005). Senada dengan pendapat sebelumnya, Soetomo (2006) juga mengemukakan bahwa kondisi tersebut kemudian akan berimbas pada terbukanya isolasi melalui peningkatan akses terhadap informasi, kesempatan-kesempatan ekonomi, serta tumbuhnya kepercayaan diri, dan dapat menjadi komponen dari modal sosial (Fukuyama, 2002).

Berdasarkan beberapa pendapat mengenai pemberdayaan masyarakat di atas dapat disimpulkan bahwa pemberdayaan masyarakat merupakan sebuah proses transfer kekuasaan yang seharusnya tidak mengandung unsur paksaan agar masyarakat memiliki kemampuan yang lebih besar untuk mengontrol kehidupannya. Proses transfer kekuasaan tersebut berarti juga memberikan ruang yang lebih terbuka bagi masyarakat yang tadinya kurang berdaya untuk dapat berpartisipasi dalam pembangunan.

\section{METODE PENELITIAN}

Penelitian ini merupakan sebuah studi pustaka yang bertujuan menjawab tujuan penelitian melalui pengkajian terhadap berbagai literatur pada jurnal yang bereputasi, buku, maupun working paper yang relevan dengan topik penelitian sebagai sumber data. Menurut Mestika (2008) studi pustaka merupakan serangkaian kegiatan yang berkenaan dengan metode pengumpulan data, membaca, dan mencatat, serta mengolah bahan penelitian. Data pustaka juga tetap andal dalam menjawab persoalan penelitian, sehingga diharapkan 
peneliti dapat memperoleh rujukan yang valid dan mampu menyajikannya ke dalam pembahasan yang mendalam, serta pada akhirnya dapat menghasilkan kesimpulan yang akurat.

\section{PEMBAHASAN}

Pemberdayaan masyarakat tidak dapat bersifat spontan dan terjadi begitu saja, akan tetapi merupakan sebuah aktivitas yang melibatkan berbagai variabel lain sehingga menjadi sebuah upaya yang terencana dan terintegrasi diantara aktor-aktor yang terlibat. Kamalipour (2002) menyatakan bahwa pembangunan merupakan proses yang bersifat partisapatori, terintegrsi, dan melibatkan stakeholder serta para penerima manfaat. Pembangunan juga bertujuan meningkatkan kualitas manusia melalui peningkatan sektorsektor sosial dalam cakupan yang luas. Tanpa keterlibatan dari semua stakeholder tidak diragukan lagi bahwa proses pembangunan, dalam hal ini pemberdayaan masyarakat sulit dilaksanakan dan dilanjutkan. Dampaknya adalah tujuan utama pemberdayaan masyarakat tidak dapat diraih.

Pemberdayaan masyarakat dalam pelaksanaannya membutuhkan kehadiran masyarakat yang tergabung dalam organisasiorganisasi lokal, sehingga semakin besar keterlibatan masyarakat dalam organisasi di lingkungan sekitar berpengaruh pada keberhasilan organisasi itu sendiri (Ohmer \& Beck, 2006). Menambahkan pendapat Ohmer \& Beck sebelumnya, Bjaras, et. al (1991) berpandangan bahwa partisipasi masyarakat membutuhkan kepemimpinan, organisasi, mobilisasi sumberdaya, dan manajemen. Berkaitan dengan partisipasi masyarakat, lebih lanjut Cornwall (2008) menyatakan betapa pentingnya memberikan perhatian yang lebih jauh kepada siapa yang berpartisipasi, dalam hal apa mereka berpartisipasi dan keuntungan apa yang mereka peroleh. Mengapa demikian? Bukan tidak mungkin justru kaum elit di pedesaanlah yang justru bertindak sebagai jaring yang mengambil keuntungan bagi dirinya sendiri (Prastyanti, 2016), begitu juga dengan stakeholder-stakeholder lain yang memiliki hidden interest yang tidak bisa lepas dari agenda yang dibawanya. Hidden interest ini hanya akan merusak semangat partisipasi dan tujuan pemberdayaan masyarakat itu sendiri karena tidak bisa dipisahkan dari agenda tertentu di belakangnya, serta digunakan sebagai alat untuk meraih keuntungan pribadi/kelompok. Trevor (2004) mengatakan bahwa ambiguitas terjadi ketika partisipasi digunakan sebagai alat untuk meraih tujuan.

Terlepas dari plus-minus partisipasi dalam pemberdayaan masyarakat, bagaimana sebuah keikutsertaan dari para stakeholder terkait justrun dapat menimbulkan konflik? Asumsinya adalah semakin banyak pihak yang berpartisipasi berdampak pada semakin banyaknya hidden interest dari para stakeholder. Pemberian ruang bagi para stakehoder dalam setiap proses pemberdayaan masyarakat justru akan memperumit keadaan terutama jika masing-masing stakeholder lebih 
mengedepankan kepentingannya. Lebih jauh lagi, apabila kepentingan pribadi/kelompok lebih besar dibanding kepentingan bersama maka hal tersebut sangat berpotensi memunculkan konflik. Agenda tersembunyi tersebut menjadikan terjadinya "pertarungan" diantara para stakeholder untuk mewujudkan agenda mereka masing-masing. Apabila hal tersebut berlanjut maka tidak mungkin benarbenar akan tercipta konflik. Konflik menjadi sulit diatasi ketika masing-masing stakeholder merasa telah memiliki peran penting dalam proses pemberdayaan masyarakat. Lebih jauh lagi, rasa memiliki peran penting tersebut menjadikan konflik menjadi semakin rumit dan sulit diatasi. Celakanya ketika para stakeholder yang terlibat merasa "lebih" dibanding lainnya, maka bukan tidak mungkin pendapat Leeuwis menjadi kenyataan. Kondisi tersebut tentu saja dapat memberikan kontribusi negatif atas pelaksanaan program pemberdayaan masyarakat itu sendiri. Namun bukankah kondisi tersebut dapat diminimalisir melalui komunikasi efektif sehingga tercipta mutual understanding diantara para pemangku kepentingan dan berpeluang untuk dapat mengatasi konflik yang terjadi?

Seperti yang sudah dipaparkan pada poin terdahulu bahwa dalam pemberdayaan masyarakat membutuhkan partisipasi dari semua stakeholder dan para penerima masnfaat, maka kesamaan pengertian diantara pihakpihak tersebut mengenai tujuan pemberdayaan masyarakat menjadi variabel yang sangat penting. Kesamaan pengertian akan turut berkontribusi atas kesamaan tindakan dan partisipasi masyarakat, yang selanjutnya akan berkorelasi pada keberhasilan pemberdayaan masyarakat itu sendiri (Prastyanti, 2012).

Kesamaan pengertian dapat tercipta salah satunya melalui proses komunikasi yang dialogis. Menurut Servaes, et. al (1996) komunikasi dialogis merupakan sebuah teori normatif dari komunikasi partisipatif. Masalahnya, teori dialogis Freire ini didasarkan pada dialog yang terjadi pada kelompok ketimbang memperkuat media seperti radio, media cetak, dan TV. Freire juga hanya memberikan sedikit perhatian pada bahasa atau bentuk komunikasi, namun lebih menitikberatkan diskusinya pada tindakan yang komunikatif. Wacana kedua mengenai komunikasi partisipatif adalah laparon akhir dari UNESCO pada pertemuan yang diadakan di Belgrade, Yugoslavia pada tahun 1977 yang lebih menekankan pada self management, akses dan partisipasi.

Sebuah laporan essay yang ditulis oleh Eleanor Novek (1999) yang berjudul "Communication and community empowerment" menganalisis betapa berperannya komunikasi dalam pemberdayaan masyarakat dan perubahan sosial. Salah satu peran yang dapat dimainkan oleh komunikasi adalah kemampuannya dalam menghubungkan kembali simpul-simpul yang terputus selama proses pemberdayaan masyarakat sehingga konflik yang terjadi dapat teratasi, karena komunikasi menciptakan hubungan diantara para stakeholder yang terlibat. Hubungan- 
hubungan yang terjalin melalui proses komunikasi tersebut didasari atas adanya kesamaan kebutuhan. Mengenai hal ini, Kertopati (1981) menyampaikan bahwa manusia cenderung memberikan perhatian yang lebih pada informasi yang sesuai dengan kebutuhannya.

\section{SIMPULAN}

Pemberdayaan masyarakat dapat terlaksana dan mencapai tujuan ketika melibatkan berbagai pihak. Partisipasi dari para stakeholder menjadikan pemberdayaan masyarakat lebih membumi karena dapat lebih mencerminkan kebutuhan nyata dari masyarakat. Namun di sisi lain justru menyisakan permasalahan karena adanya agenda tersendiri yang dibawa oleh masingmasing stakeholder sehingga konflik yang terjadi menjadi semakin kompleks dan sulit untuk dipecahkan. Sayangnya lagi bukan tidak mungkin agenda tersebut cenderung menguntungkan diri sendiri ataupun kelompoknya daripada untuk kepentingan bersama.

Dalam kondisi konflik yang terjadi akibat adanya partisipasi para stakeholder pada berbagai proses pemberdayaan masyarakat seperti tersebut di atas, komunikasi dapat mengambil peran yang sangat vital. Dalam sudut pandang komunikasi, partisipasi para stakeholder dalam pemberdayaan masyarakat pada berbagai tingkat partisipasi justru dapat menjadikan mereka memiliki ruang yang lebih terbuka untuk saling berinteraksi. Interaksi ini dapat menghubungkan kembali sekat-sekat komunikasi yang terjadi, dan pada gilirannya konflik dalam pemberdayaan masyarakat dapat diatasi ketika masing masing pihak yang berpartisipasi bersedia melakukan komunikasi dialogis sehingga tercipta mutual understanding diantara mereka.

\section{REFERENSI}

Arnsperger, Christian \& Yanis Varoufakis. (2003). Toward a Theory of Solidarity. Erkenntnis, 59 (2), 157188.

Bakti, Andi Faisal. (2004). Communication and Family Planning in Islam in Indonesia. South Sulawesi Muslim Perceptions of a Global Development Program. JakartaLeiden: INIS.

Bhattacharyya, Jnanabrata. (2004). Theorizing Community Development. Journal of the Community Development Society, 34(2), 5-34.

Bjãrås, Gunilla, Boj. A. Haglund, Susan B. Rifkin. (1991). A New Approach to Community Participation Assessment. Journal of Health Promotion International, 6 (3),199206 
Cornwall, Andrea. (2008). Unpacking 'Participation': models, meanings and practices. Community Dev Journal, 43 (3), 269-283.

Fukuyama,Francis. (2002). The Great Disruption, Hakekat Manusia dan Rekonstitusi Tatanan Sosial. Yogyakarta: Penerbit Qalam.

Garfinkel, Michelle. R \& Skaperdas, Stergios. (2000). Conflict without Misperceptions or Incomplete Information. How the Future Matters. Journal of Conflict Resolution, 44(6),793-807.

Jacobson, Thomas L \& Store, Douglas. (2004).

Communication Theory. Development Communication and Participation: Applying Habermas to a Case Study of Population Programs in Nepal. International Communication Associaton, 14 (2), 99-121.

Kamalipour, Yahya R.(2002). Global Communication. Belmont. California: Wadsworth.

Kertopati, Ton. (1981). Dasar - Dasar Publisistik. Jakarta: Bina Cipta.

Kwiatkowski, L. (2005). NGOs, Power and Contradiction in Ifugao, the Philippines. Urban Anthropology \& Studies of Cultural Systems \& World Economic Development, 34 (4), 385-436.
Leeuwis,Cees, (2000). Reconceptualizing Participation for Sustainable Rural Development: Towards a Negotiation Approach . Development and Change, 31 (5), 931-959

Littlejohn, Stephen W \& Foss, Karen A (2011. Theories of Human Communication: Tenth Edition. Illinois: Waveland Press, Inc.

Mardikanto, Totok. (2010). Komunikasi Pembangunan. Acuan bagi Akademisi, Praktisi, dan Peminat Komunikasi Pembangunan. Solo: Sebelas Maret University Press.

Mestika, Zed. (2008). Metode Penelitian Kepustakaan. Jakarta: Yayasan Obor Indonesia.

Novek, Eleanor M. (1999). Communication and community empowerment. Journal Peace Review. A Journal of Social Justice, 11 (1), 61-68.

OACD/Noya A. Clarence E. (2009). "Community Capacity Building: fostering economic and social resilience. Project Outline and Proposed Methodology, “ 26-27 November 2009, working document, CFE/LEED, OECD.

Ohmer, Mary \& Elizabeth Beck. (2006). Citizen Participation in Neighborhood Organizations in Poor Communities and Its Relationship to Neighborhood and Organizational Collective Efficacy. Journal of Sociology \& Social Welfare, 33 (1), 179-202. 
Page, Nannette \& Cheryl E. Czuba. (1999).

Empowerment: What Is It?. Journal

of Extension, 37 (5).

Pigg, E. Kenneth. (2002). Three Faces of Empowerment: Expanding the Theory of Empowerment in Community Development. Journal of the Community Development Society, 33 (1), 107-123.

Prastyanti, Shinta. $\left(\begin{array}{llll}2 & 0 & 1 & 2\end{array}\right)$. M e n g k o m u i k a s i k a n Pembangunan Pada Masyarakat Pedesaan, Acta Diurna, 8 (1), 1015.

Prastyanti, Shinta (2016). Kemiskinan dan Pembangunan Pedesaan. Acta Diurna, 12 (1), 1-15.

Rahman, M.A. (1993). People's selfdevelopment: perspectives on participatory action research - a journey through experience. London: Zed.

Rahim, M. Azfalur. (2000). Empirical Studies On Managing Conflict. International Journal of Conflict Management, 11 (1), 5-8.

Rogers, E. $M$ and Kincaid, D.L. (1986). Communication Networks; Towards a New Paradigm for Research. New York: The Free Press.
Schuftan, Claudio. 1996. The community development dilemma: what is really empowering?. Community Development Journal, 31(3), 260264.

Servaes, Jan, Thomas L. Jacobson, Shirley A. White. (1996). Participatory Communication for Social Change. New Delhi, Thousand Oaks. London: Sage Publications.

Shortall, Sally. (2008). Are rural development programmes socially inclusive? Social inclusion, civic engagement, participation, and social capital: Exploring the differences. Journal of Rural Studies, 24(4), 450-457.

Soetomo. (2006). Strategi-Strategi Pembangunan Masyarakat. Yogyakarta : Pustaka Pelajar.

Sympson, Lynn, Leanne Wood, \& Daws, Leoni. (2003). Community capacity building: Starting with people not projects. Community Development Journal, 38 (4), 277-286.

Tjosvold, Dean. (1998). Cooperative and Competitive Goal Approach to Conflict: Accomplishments and Challenges. Journal of Applied Psychology, 47 (3), 285-313. 
Tjosvold, Dean \& Haifa F. Sun. (2003).

Openness Among Chinese in

Conflict: Effects of Direct

Discussion and Warmth on

Integrative Decision Making

Journal of Applied Psychology, 33

(9), 1878-1897.

Trevor, Parfitt. (2004). The ambiguity of participation: a qualified defence of participatory development. Third

World Quarterly, 25 (3), 537-555. 